\title{
Evaluation the Reactivity of a Peptide-Based Monoclonal Antibody with Drug Resistant Pulsotypes of Acinetobacter Baumannii as Potential Therapeutic Approach
}

\section{Omid Yeganeh}

Islamic Azad University Tehran North Branch https://orcid.org/0000-0003-0512-7193

Mahdi Shabani ( $D$ msshabani@yahoo.com)

Shahid Beheshti University of Medical Sciences

\section{Parviz Pakzad}

Islamic Azad University

Nariman Mosaffa

Shaheed Beheshti University of Medical Sciences

Ali Hashemi

Shaheed Beheshti University of Medical Sciences

\section{Research}

Keywords: Acinetobacter baumannii, Antibiotic resistance, Monoclonal antibody (mAb), Outer membrane protein $\mathrm{A}(\mathrm{OmpA})$, Passive immunization, Antimicrobials

Posted Date: November 1st, 2021

DOI: https://doi.org/10.21203/rs.3.rs-1010382/v1

License: (c) (i) This work is licensed under a Creative Commons Attribution 4.0 International License.

Read Full License 


\section{Abstract \\ Background:}

Acinetobacter baumannii is an opportunistic and antibiotic-resistant pathogen that predominantly causes nosocomial infections. There is urgent need for development nonantibiotic-based treatment strategies. We developed novel monoclonal antibody $(\mathrm{mAb})$ against a peptide of conserved outer membrane protein $\mathrm{A}(\mathrm{OmpA})$ and evaluated its reactivity with different pulsotypes of $A$.baumannii.

\section{Materials and Methods:}

Peptide derived from A.baumannii OmpA was conjugated to keyhole limpet hemocyanin and injected into Balb/c mice. Splenocytes of immunized mice were fused with SP2/0 myeloma cells followed by selection of antibody-producing hybridoma cells. After screening of different hybridoma colonies by ELISA, one monoclone was selected as 3F10-C9 and the antibody was tested for reaction with five different Acinetobacter pulsotypes that were resistant to carbapenem antibiotics. The affinity constant was measured by ELISA. The ELISA, Western blotting, indirect immunofluorescence (IFA), and in vitro Opsonophagocytosis assays were used to evaluate the reactivity of generated mAb.

\section{Results:}

The anti-OmpA antibody reacted with the immunizing peptide and had a high affinity (around $1.94 \times 10^{-}$ ${ }^{9} \mathrm{M}$ ) for its antigen in the ELISA. Specific binding of mAb to OmpA was confirmed in Western blot. IFA assays revealed that $\mathrm{mAb}$ recognized specific OmpA on the pulsotypes. Opsonophagocytosis assays showed that the mAb increased bactericidal activity of macrophage cells. The antibody function was higher in the presence of serum complement.

\section{Conclusion:}

The peptide-based $\mathrm{mAb}$ demonstrated optimal performance in laboratory experiments which may be appropriate in investigation on OmpA in Acinetobacter pathogenesis and development of passive immunization as novel therapeutic approach.

\section{Highlights}

- Acinetobacter remains a common cause of nosocomially acquired device-related infections and data concerning the Acinetobacter pathology are insufficient and controversial. It harbors antibiotic resistance genes and tends to develop resistance to many antimicrobial agents. 
- OmpA is an evolutionary conserved protein and a predominant cell surface antigen in the most gramnegative bacteria which have the potentials to be a candidate target for antimicrobial therapy.

- In the present study, the peptide-based mAb, 3F10-C9, showed positive reactions with OmpA of drugresistant $A$. baumannii pulsotypes in some laboratory tests that may be appropriate to development of immunological tools required for $A$. baumannii research.

- The mAbs that target OmpA may open new possibilities for immunotherapy by providing an excellent cellular targeting and development of passive immunization.

- As good companions of the antimicrobials, antibodies could confer sufficient protection against $A$. baumannii infections with no effect on host microbiota diversity.

\section{Introduction}

Acinetobacter baumannii has become an increasingly hospital-acquired infections associated with a wide spectrum of human diseases, particularly among immunocompromised patients who have a weakened immune system due to an underlying disease or genetic disorder, with the ability to accumulate drug resistance mechanisms and thus the emergence of strains resistant to common commercial antimicrobial agents (1). The growing resistance to beta-lactam drugs, carbapenems, and even colistin antibiotics complicates an effective antibiotic therapy and raises the need for new strategies to prevent and treat infections caused by $A$. baumannii $(2,3)$. The acquired resistance profiles including multidrugresistant (MDR), extensively drug-resistant (XDR) and pandrug-resistant (PDR) bacteria are often responsible for healthcare-associated infections which usually lead to higher medical costs, prolonged hospital stays, and increased mortality throughout the world (4). Hereupon, the healthcare institutions must be aware of infections caused by members of the genus Acinetobacter. It is authenticated that neutrophils, macrophages, complement system, and specific antibodies are necessary to effective disease control and elimination of these extracellular bacteria $(5,6)$. Data concerning the impact of MDR $A$. baumannii are insufficient and controversial. There are currently no approved vaccine offering significant protective efficacy against acute $A$. baumannii infection $(7,8)$. Beyond that, compared to other bacteria, a narrow-spectrum antibiotic is only effective against $A$. baumannii and in the pipeline to treat or control of this gram-negative bacterium (9). There is an instant necessity to enforce infection control measures and antimicrobial stewardship programs to prevent the further spread of drug resistant Acinetobacter species and to postpone the increasing resistance in other bacteria (10).

Despite an antibiotic or a small peptide, whose function is simply to bind and modulate a target, the antibodies possess the other capabilities due to their Fc region including opsonophagocytic activity, agglutination process, and activating the complement system. In this regard, the antibodies are essential in cases such as, triggering immunity against $A$. baumannii, induction of protective mechanisms, blocking of bacterial attachment to the epithelial cells, the opsonization process, and the complementdependent degradation of the bacteria (11). Considering the important role of antibodies in humoral immunity, monoclonal antibody $(\mathrm{mAb})$ could be designed to interact with specific targets and provide complementary protection as an immunotherapy or passive immunization $(12,13)$. Outer membrane 
protein $\mathrm{A}(\mathrm{OmpA})$, one of the major outer membrane proteins in gram-negative bacteria, is an essential virulence factor that mediates bacterial biofilm formation, eukaryotic cell infection, antibiotic resistance, virulence, and immunomodulatory mechanisms (14). OmpA is a class of $\beta$-barrel integral membrane proteins settled in bacterial outer membrane, whose molecular mass ranges from $26 \mathrm{kDa}$ to $38 \mathrm{kDa}$ (15). In the past few years, studies have shown that the amino acids of this protein from a variety of clinical isolates are highly conserved in evolution (> $89 \%$ ) and without any homology with the human proteome $(16,17)$. Therefore, OmpA has been considered as an antigenic candidate in development of mAbs against $A$. baumannii (18-20). The mAbs that target OmpA may open new possibilities for immunotherapy by providing an excellent cellular targeting and could be useful for studying the physiological functions of this evolutionarily conserved protein. More accurate techniques will be used in the future clinical trials to identification and even biotherapy of this opportunistic nosocomial pathogen.

This study aimed to evaluate the reactivity a peptide-based mAb with OmpA protein in antibiotic resistance pulsotypes of $A$. baumannii and survey whether the conserved surface-exposed OmpA in these different pulsotypes of $A$. baumannii holds the potentials to be an antigen candidate for passive immunotherapy in the future.

\section{Materials And Methods}

\section{Preparation of OmpA-derived peptide as an immunogen}

Based on previous in-silico design and bioinformatics analysis, a 27 amino acid peptide (VTV TPL LLG YTF QDS QHN NGG KDG NLT) at N-terminal region located at 24-50 position derived from OmpA of $A$. baumannii was designed and used as a safe and suitable immunogen for mice immunization (21). As previously described, the OmpA antigenic epitopes were predicted using different tools with the highest score and based on hydrophobicity, antigenicity, flexibility, mobility, accessibility, polarity, exposed surface, and coils. Then, among five OmpA consensus epitopes, one of the novel synthetic peptides was selected [peptide 1 (amino acids located in the 24-50 position of the OmpA protein)] that had elicited higher immune responses (21).

\section{Mice immunization procedure}

In this study, which is a new experiment in the production of antibodies $(m A b)$ against microbial drug resistance, Balb/c mice (Royan Institute, Tehran, Iran) were used for immunization. Female mice aged 6-8 weeks were intraperitoneally immunized by injecting $25 \mu \mathrm{g}$ of the mentioned peptide on days $0,21,35,49$, 63, and 77 (22). To induce an acceptable immune response, the first injection was carried out using complete Freund's adjuvant (Sigma-Aldrich, Saint Louis, USA), while the other five injections were performed using incomplete Freund's adjuvant (Sigma-Aldrich, Saint Louis, USA). Ten days after the last injection, mice were tail-bled and the sera were assayed for antibody molecules against antigenic peptide in an indirect ELISA test. Mouse with the highest titer of anti OmpA-peptide were selected for further steps. Finally, three days before the cell fusion, $20 \mu \mathrm{g}$ of peptide-KLH (without any adjuvant) were injected intravenously. 


\section{Evaluation of mice immune response by enzyme-linked immunosorbent assay (ELISA)}

ELISA plate wells (Greiner-Bio-One, Italy) were coated with $50 \mu \mathrm{L}$ OmpA-derived peptide $(10 \mu \mathrm{g} / \mathrm{mL}$ ) overnight at $4^{\circ} \mathrm{C}$. After washing three times with PBS-Tween 20 (0.05\%) (Sigma-Aldrich, St Louis, Mo, USA), the plate was blocked with $2.5 \% \mathrm{BSA}$ at $37^{\circ} \mathrm{C}$ for one hour and also at $4^{\circ} \mathrm{C}$ for three hours. Wells were then washed three times. To evaluate the immune response of mice, different dilutions of mice serum were added to the wells starting from $1: 500$ and at $37^{\circ} \mathrm{C}$ for one hour. Then, HRP-conjugated rabbit antimouse Ig (1:1000; Avicenna Research Institute, Tehran, Iran) was added and incubated for one hour at $37^{\circ} \mathrm{C}$. After washing, tetramethylbenzidine (TMB) (DNAbiotech Co, Iran, Cat No: DB9510) was added to each well and the plates were incubated at room temperature (RT) in the dark. After 10 minutes, $15 \mu \mathrm{L}$ stopping solution $\left(20 \% \mathrm{H}_{2} \mathrm{SO}_{4}\right)$ was added to each well. The optical densities (OD) of the reactions were measured at $450 \mathrm{~nm}$ by an ELISA reader (Anthos 2020, Salzburg, Austria). The mouse with the highest titer of specific antibody was considered for cell fusion and hybridoma generation. To screen for antibody production by hybridoma cells, the same procedure was performed on the culture supernatants.

\section{Cell culture requirements}

One of the most important and common methods for producing $\mathrm{mAb}$ in vito is to grow the hybridoma cells in batches and purify the mAb from the culture medium. In general, the cultured cells require a sterile culture medium containing nutrients for growth and proliferation. The culture medium must be sufficiently stable in terms of $\mathrm{pH}$ and temperature. Therefore, factors such as sterility, $\mathrm{pH}$, nutrients, and proper temperature play a major role in the cell culture. Following this, we used the RPMI-1640 (Gibco by life technologies, USA), and DMEM/F-12 (Gibco, USA) growth medium in culture of hybridoma cells and RAW 264.7 cells, respectively

\section{Cell fusion process}

One of the well-immunized mice was chosen and used for fusion process. In order to develop suitable hybridoma cells, mouse myeloma $\mathrm{SP}_{2} / 0$ cells and splenocytes of the immunized mouse were washed with pre-warmed RPMI medium ( $\mathrm{pH}: 7.2)$ and then mixed in a ratio of $1: 5$ respectively. After rinsing the cell mixture, pre-warmed $\left(37^{\circ} \mathrm{C}\right) 50 \%$ polyethylene glycol (PEG) 1500 (HybriMax, Sigma-Aldrich, USA), as a non-ionic hydrophilic polymer, was added to the cell pellet slowly with continuous mixing (23). After pouring $20 \mathrm{ml}$ of the wash medium, cells were centrifuged at $20^{\circ} \mathrm{C}$ for 5 minutes at $1000 \mathrm{rpm}$ (or $500 \mathrm{G}$ ). Hypoxanthine-aminopterin-thymidine (HAT) supplemented medium (Sigma, USA) was then added to the wells and hybridoma cells were allowed to grow (24). For better growth of hybridomas, fetal bovine serum (FBS) (Gibco, USA) was used at concentrations of $10 \%$ or $20 \%(\mathrm{v} / \mathrm{v})$ as an enrichment in the culture medium (25). The cell culture supernatants were then tested for the mAb by ELISA as a mentioned above. Hence, among the grown hybrid cells, the mono clones capable of producing mAbs were screened. Then, a mono clone with freshly condition and without possible contamination were selected as 3F10-C9 clone.

\section{Isotype determination of mAb by capture ELISA}


Goat anti-mouse IgG1, IgG2a, IgG2b, IgG3, IgA, and IgM subclass specific antibodies including Lambda $(\lambda)$ and Kappa (к) at 1/1000 dilution (Sigma-Aldrich-ISO2 MSDS, USA), with $50 \mu \mathrm{l} /$ well, were adsorbed on to the wells of a microtitre ELISA plate (SPL, Korea). The ELISA plate was incubated at $37^{\circ} \mathrm{C}$ for one hour and blocked with BSA $2.5 \%$ and then washed three times with $300 \mu \mathrm{l} /$ well PBS-Tween $0.05 \%$. The supernatant of the 3F10-C9 clone was added in the amount of $100 \mu$ lo each well. Also, PBS $1 \mathrm{x}$ was added instead of 3F10-C9 mAb to each well as a negative control. After 90 minutes incubation at $37^{\circ} \mathrm{C}$ and washing, $50 \mu \mathrm{l} /$ well of peroxidase-conjugated rabbit anti-mouse Ig (Avicenna research institute, Tehran, Iran) (1:1000) were added to each well. After 30 minutes incubation at $37^{\circ} \mathrm{C}$ and washing, $50 \mu \mathrm{l}$ fresh TMB substrate were added and incubated for 12 minutes in the dark at RT. Then, the colorimetric reaction was stopped by adding $20 \mu \mathrm{l}$ of $20 \% \mathrm{H}_{2} \mathrm{SO}_{4}$ per well. The ELISA plate was read at $450 \mathrm{~nm}$ absorbance by an automated microplate reader and the mAb isotype was identified.

\section{Determination of affinity constant}

The affinity constant $\left(\mathrm{K}_{\mathrm{aff}}\right)$ of $\mathrm{mAb}$ from the clone 3F10-C9 was determined by ELISA method as previously described (26). All reactions were done in a sealed (to prevent evaporation) microtitre polystyrene plate (Maxisorp, Nunc, Denmark) with all reaction volumes of $50 \mu \mathrm{l}$. The ELISA plate, precoated with five different concentrations of peptide $(5000,2500,1250,625,312.5 \mathrm{ng} / \mathrm{ml})$, were separately incubated with serial dilutions of the mAb. Plate washing was performed three times with PBS-Tween after each incubation for $1 \mathrm{~h}$ at $37^{\circ} \mathrm{C}$. Sigmoid curves were then plotted using the $O D_{450}$ values against the antibody concentrations. The half of maximum OD (OD-50) on each curve was determined at $450 \mathrm{~nm}$. Then, antibody concentration was assigned on the $\mathrm{X}$-axis corresponding to OD-50 of each antigen curve. The $K_{\text {aff }}$ was then calculated using the following equation:

$K_{a f f}=(n-1) / 2\left(n\left[A b^{\prime}\right]-[A b]\right),(n=[A g] /[A g '])$, where $\left[A b^{\prime}\right]$ and $[A b]$ are in their own relative OD-50, respectively.

\section{Affinity purification of generated $\mathrm{mAb}$}

3F10-C9 mAb was affinity purified using a column of pre-activated resin, CNBr-activated sepharose 4B (GE Healthcare, Uppsala, Sweden), conjugated to the OmpA-peptide. The elution was performed using $0.1 \mathrm{M}$ glycine- $\mathrm{HCL}(\mathrm{pH}: 2.7)$. The eluted antibody was dialyzed overnight against PBS $1 \mathrm{x}(\mathrm{pH}: 7.2)$ at $4^{\circ} \mathrm{C}$, and the antibody reactivity was measured by ELISA as described above.

\section{Preparation of bacterial samples}

Bacterial samples were collected from carbapenem-resistant $A$. baumannii in hospitals that have been previously isolated and studied (27). These isolates harbored resistance genes such as OXA-23, OXA-24 and OXA-58 and subsequently were analyzed for possible presence of resistance indices including Ambler class A, metallo- $\beta$-lactamases (MBLs), carbapenem-hydrolysing class D $\beta$-lactamases, and insertion sequence of ISAba1. The genetic relatedness between the studied isolates was analyzed using pulsed-field gel electrophoresis (PFGE) (27). Among different clonal pulsotypes of Acinetobacter 
baumannii, we selected five defined isolates including pulsotypes $A$ to $E$ and subjected them to various experiments.

\section{Western blot analysis}

A single clone of each bacterial isolates was harvested from the bacterial culture and then centrifuged (5000 rpm for 5 minutes). Bacterial pellets were suspended in $1 \mathrm{ml}$ lysis buffer (lysis buffer: $150 \mathrm{mM}$ Sodium chloride, $2 \mathrm{mM}$ EDTA, $1 \mathrm{mM} \mathrm{NaF}, 40 \mathrm{mM} \mathrm{Na}_{4} \mathrm{P}_{2} \mathrm{O}_{4}, 0.1$ \% SDS, $50 \mathrm{mM}$ Tris pH 7.4, 1\% glycerol, and $1 \%$ Triton $\mathrm{X}-100$ ). The suspension was boiled for 5 minutes and sonicated three times for 20 seconds (Ultrasonic Apparatus XO-650, Xianou, Nanjing, China). The supernatant of sonicated proteins from $A$. baumannii (pulsotypes A to $\mathrm{E}$ ) were considered as the native OmpA lysates, which were prepared by breaking Acinetobacter pulsotypes.

As stated, OmpA of $A$. baumannii is closely similar to Escherichia coli OmpA and OprF of Pseudomonas aeruginosa (28). The supernatants from sonicated E. coli (ATCC 25922) and P. aeruginosa (ATCC 27853) lysates were used as quality control to evaluate antibody reactivity with the samples loaded in the gel. Accordingly, bacterial lysates were loaded at $15 \mu \mathrm{g}$ on each well of $10 \%$ bis-tris gel with SDS running buffer. After electrophoresis, resolved proteins were transferred from the gel onto Immobilon-PVDF blotting membrane (Millipore, Billerica, Massachusetts, USA). The membrane was blocked overnight at $4^{\circ} \mathrm{C}$ with $5 \%$ non-fat dry milk (Sigma, Millipore, USA) in PBS-Tween 20 (0.05\%). After gentle washing with PBS-Tween, 3F10-C9 mAb $(20 \mu \mathrm{g} / \mathrm{ml})$ was added to the membrane and incubated for 90 minutes at RT. The membrane was washed extensively with PBS-Tween and incubated with HRP-conjugated rabbit antimouse IgG (Avicenna research institute, Tehran, Iran) (1:2000) for $1 \mathrm{hr}$ at RT, followed by washing and developing with DAB (3,3'-Diaminobenzidine) detection system (Thermo Scientific, PI34002, USA).

\section{Indirect immunofluorescence assay (IFA)}

An indirect immunofluorescence assay (IFA) for the detection of produced mAb to the surface antigen OmpA was developed. About $1.5 \times 10^{6}$ of each Acinetobacterpulsotype (isolates A to E) and also $E$. coli were prepared and washed twice with PBS pH 7.2, and then centrifuged at $5000 \mathrm{rpm}$ for 5 minutes. After washing, bacterial cells were incubated with $100 \mu \mathrm{l}$ of purified 3F10-C9 mAb $(20 \mu \mathrm{g} / \mathrm{ml})$ as the primary antibody for one hour at $37^{\circ} \mathrm{C}$. After washing twice with PBS-Tween, the subject microtubes were incubated with $100 \mu \mathrm{l}$ of fluorescein isothiocyanate (FITC) conjugated sheep anti-mouse immunoglobulin as secondary antibody (Dilution 1:500; Avicenna research institute, Tehran, Iran) for 45 minutes. After washing with PBS-Tween, $50 \mu \mathrm{L}$ of each sample was placed on the slide and covered with coverslip to observe microscopically under ultraviolet light.

\section{Opsonophagocytic killing assay}

The opsonization assay was performed to examine the antibody which act to coat the bacterial cell wall and prepare it for ingestion $(12,17)$. Five pulsotypes of $A$. baumannii were cultured overnight in LuriaBertani broth medium at $37^{\circ}$, then passaged to mid-log growth, rinsed, and suspended in a sterile PBS 1x. Murine macrophage RAW 264.7 cells were cultured at $37^{\circ} \mathrm{C}$ in $5 \% \mathrm{CO}_{2}$ in DMEM medium with $10 \%$ 
FBS. The 264.7 cells were activated by four days of exposure to $1 \mu \mathrm{g} / \mathrm{ml}$ lipopolysaccharide (LPS) (Sigma-Aldrich, L2880, USA). LPS-differentiated RAW cells were transferred from the culture flask to a microtiter plate $\left(\sim 2 \times 10^{6} \mathrm{cells} / \mathrm{ml}, 80 \mu \mathrm{l} /\right.$ well). Then, five isolates of $A$. baumannii were added distinctly to each well of the plate $\left(\sim 1 \times 10^{6} \mathrm{CFU} / \mathrm{ml}, 10 \mu \mathrm{l} /\right.$ well $)$. The 3F10-C9 mAb at a concentration of $50 \mu \mathrm{g} / \mathrm{ml}$ were then added to each well $\left(10 \mu \mathrm{l} /\right.$ well) for 6 hours at $37^{\circ} \mathrm{C}$. For complement studies, non-immune mouse serum was added to the wells $(10 \mu \mathrm{l} /$ well) in both of active and heat-inactivated forms in order to create conditions with complement and without complement, respectively. For quality control, Escherichia coli ATCC 25922 strain was used as a gram-negative bacterium that has a relative structural similarity to Acinetobacter (3). (Notably, if available, the A. baumannii knock-out of the OmpA gene can be used for the quality control). In addition, as a negative control, a non-specific monoclonal antibody with the IgG isotype was used instead of the 3F10-C9 mAb in the presence and absence of the serum complement. After 6 hours incubation of mixtures with gentle shaking, the supernatant of each well was removed and quantitatively plated in Mueller-Hinton agar. Then, the number of bacteria colony forming units (CFU) of each well were counted after an overnight culture and followed by calculation the approximate rate of bacterial mortality (29).

\section{Ethics statement}

This work was carried out under the supervision of the institutional research ethics committee of Islamic Azad university, science and research branch (Approval ID: IR.IAU.SRB. REC. 1398. 064).

\section{Statistical analysis}

All statistics analyses were run using GraphPad Prism 8 software. Evaluation of the relationship between bacterial killing and type of opsonin substances (mAb or Isotype control antibody), in two groups with complement and without complement, was studied using the chi-square test separately for different pulsotypes of bacteria. Differences were considered significant if the $p$ value was $<0.05$.

\section{Abbreviations}

ELISA: enzyme-linked immunosorbent assay

OmpA: outer membrane protein A

IFA: indirect immunofluorescence assay

$\mathrm{KLH}$ : keyhole limpet hemocyanin

BSA: bovine serum albumin

mAb: monoclonal antibody

MDR: multidrug-resistant 
XDR: extensively drug-resistant

PDR: pandrug-resistant

$\mathrm{kDa}$ : kilodalton, a unit of molecular mass equal to 1000 daltons

TMB: tetra methyl benzidine

$K_{\text {aff: }}$ affinity constant

PBS: Phosphate buffered saline solutions

MBLs: metallo-ß-lactamases

OXA genes: a group of carbapenem-resistant OXA-type $\beta$-lactamases that have been identified in $A$. baumannii

PFGE: pulsed-field gel electrophoresis

mM: millimolar

RT: room temperature

CFU: colony-forming unit

DAB: 3,3'-Diaminobenzidine

\section{Results}

Using a dominant antigen that helps to diagnosis and stimulate protective immunity against various $A$. baumannii strains would be helpful. We employed a peptide-based antibody generation for producing mAb against the OmpA antigen which has high expression levels in Acinetobacter. In this respect, bovine serum albumin (BSA) and keyhole limpet hemocyanin (KLH) were selected as the carrier proteins to be conjugated with OmpA-specific peptide. Correct conjugation of the peptide to carrier proteins were assessed by the SDS-PAGE electrophoresis. The change in mobility shift of peptide-BSA conjugate on SDS-PAGE gel demonstrated the efficiency of conjugation (Figure 1). Accordingly, peptide-KLH was used to immunize Balb/c mice and peptide-BSA was applied to confirm our conjugation. Following mice immunization, the titers of anti-OmpA antibodies were measured in mice serum by ELISA test. Mice serum were diluted from 1:500 to 1:16000 and acquired data showed that one of the mice was well prepared for cell fusion (Figure 2). After fusion between splenocytes of immunized mouse and myeloma SP2/0 cells, supernatants of growing hybridoma cells were screened based on reactivity with OmpApeptide by ELISA. Among several positive clones, one monoclone, designated as 3F10-C9, had a strong reactivity with OmpA. After the growth and proliferation of the cells of 3F10-C9 clone, subsequent tests were carried out with the mAb from this clone (Figure 3 ). 


\section{Isotype determination and affinity measurement}

The ELISA method was applied for isotype determination of produced anti-OmpA mAb. In this regard, isotype of mAb 3F10-C9 was determined to be IgG1 with kappa $(\mathrm{K})$ light chain. The affinity constant $\left(\mathrm{K}_{\mathrm{aff}}\right)$ of 3F10-C9 mAb was also calculated by home-made ELISA as described in the methods section. In this regard, different dilutions of the mAb were separately applied to five different peptide concentrations. Sigmoid curves were plotted to represent the relationship of $\mathrm{OD}_{450}$ value versus logarithmic mAb concentration in five different antigen concentrations (Figure 4). The affinity constant was then calculated $1.94 \times 10^{-9} \mathrm{Mol}$.

\section{Western blot analysis}

In Western blotting, DAB substrate enabled chromogenic detection of HRP-activity at the site of OmpA protein. Accordingly, Western blot analysis indicated that 3F10-C9 mAb appropriately reacted with the OmpA present on isolates of $A$ to $E$ of $A$. baumannii and with OmpA-peptide in the BSA-peptide column. As a result, Western blot experiment showed that 3F10-C9 mAb recognized OmpA molecules around 28 $\mathrm{kDa}$ molecular weight. Further, the mAb detected the peptide molecules around $65 \mathrm{KDa}$ which were conjugated to the BSA carrier protein (Figure 5). There was no reaction between the 3F10-C9 mAb and lysates of E. coli and P. aeruginosa.

\section{IFA assay and mAb recognition for OmpA}

The reactivity of 3F10-C9 mAb with native OmpA on bacterial surface was investigated by IFA assay. Acquired images revealed that the antibody recognized extracellular OmpA molecules on five various pulsotypes (A-E) of A. baumannii. No reaction was observed with the mAb and E. coli cells (Figure 6), which was probably due to the specificity of the antibody. These data support the idea that Acinetobacter OmpA is a conserved and specific protein.

\section{The 3F10-C9 mAb increases macrophage-mediated bactericidal activity in vitro}

An in vitro macrophage opsonophagocytosis assay was operated to analyze whether opsonization of experimental strains with the 3F10-C9 mAb increased bactericidal activity. The bactericidal activity of interest was reflected by the initial CFU minus the CFU after 6 hours of incubation at $37^{\circ} \mathrm{C}$ in the presence of activated murine macrophage RAW 264.7 cell line with and without serum complement. Compared to IgG1 isotype control, the opsonization with 3F10-C9 mAb significantly increased bactericidal activity of macrophage cells against the various Acinetobacter pulsotypes $(P<0.001)$, and also the approximate rate of bacterial death increased significantly in the presence of serum complement factor. However, the 
isotype control in the presence or absence of complement did not have a significant effect on bacterial mortality. In addition, the evidence demonstrated that the pulsotypes were better opsonized and consequently more harvested than E. coli bacteria in the presence of 3F10-C9 mAb and macrophage cells

(Figure 7). These results showed that the increased macrophage-mediated bactericidal activity in the presence of 3F10-C9 mAb could support the hypothesis of the therapeutic potential of the specific antibodies against bacteria.

\section{Discussion}

In recent years, $A$. baumannii is believed to have accounted for a considerable proportion of conditioned nosocomial infections, such as ventilator-associated pneumonia (VAP), catheter associated urinary tract infections, and infections of bloodstream, wound, or surgical wards in the hospitals. These hospitalacquired infections are common across all parts of the world, with a relative prevalence of $10-15 \%$ in developed countries and up to $30 \%$ in developing countries, and are often resistant to most antibiotics which usually lead to increased treatment costs, overuse of antibiotics, and antibiotic resistance $(3,4)$. Lack of antibiotics that remain active against refractory isolates of $A$. baumannii suggests possible roles of vaccination and passive immunotherapy as alternative strategies to fight these nosocomial infections. In vaccine development programs, some antigenic cell components such as, inactivated whole cells, outer membrane vesicles (OMVs), outer membrane complexes (OMCs), outer membrane proteins (OMPs), and even capsular polysaccharides have been shown to be effective in protection against $A$. baumannii challenge in animal models $(30,31)$. However, the solubility, variability and immunogenicity of these antigens indicate some limitations to delivery of protective vaccines (7). On the other hand, an active vaccine may cause undesirable or deleterious immune responses that can affect the safety and efficacy of the vaccine in clinical trials (32). In this case, the use of passive immunotherapy including direct injection of approved monoclonal antibodies is recommended (12). Bacterial surface sight is widely used to identify and screen of antigenic determinants, following the production of high-affinity antibodies that are able to detect surface antigens $(33,34)$. It was affirmed that immunization with the major foreign proteins leads to significant rise in protective immune responses, and antibodies against various outer membrane proteins protect passively laboratory animal models $(17,18,35)$. As mentioned, OmpA is an evolutionary conserved protein and a predominant cell surface antigen in the most gram-negative bacteria that participates in cases such as facilitating the bacterial acclimatization to environmental stresses, reaction with the epithelial cells, and induction apoptosis in host cells $(36,37)$. Despite potential levels of OmpA as strong immunogen, other studies have shown that OmpA is soluble and biologically active when recovered from the supernatant of Acinetobacter culture, but insoluble when expressed as a recombinant protein (38). On the other hand, molecular interactions indicated that OmpA was naturally toxic to host cells and clinical isolates of $A$. baumannii overexpressing OmpA ascertained higher morbidity and even mortality in patients $(39,40)$. Therefore, we decided to identify the surface peptides related to the $\mathrm{N}$-terminal part of the OmpA protein and then used it as a safer antigen to produce peptide-based mAbs. 
Since, most of the proteins within the Acinetobacter proteome are uncharacterized, the study of OmpA protein and the identification of extra-loop immunogenic peptides is a rewarding endeavor. In view of this, it has been stated that OmpA-designed peptides could serve as an appropriate candidate in diagnostic kits and predicted to be more immunogenic which may provide more permanently protection against A.baumannii in immunotherapy models $(21,41)$. A peptide fragment is thought to be a soluble antigen which could be used as a valuable biomaterial in research fields such as biological experiments, antibody engineering, medical diagnostics, drug targeting, and biotherapy. Likewise, an epitope or antigenic determinant is defined as the portion of a larger antigen that generally binds to an antibody that secreted by B-lymphocytes (42).

With bioinformatics technique and peptide design principles, an epitope with desirable properties could be prepared in quantity in order to raise specifically its protective immune responses. This suggests that a properly-selected peptide from OmpA could serve as a feasible tool with low toxicity for antibody production which is able to protect the host against $A$. baumannii. It has been shown that immunization with a conserved region of Acinetobactervirulence factor can increase biofilm degradation and counteract Acinetobacter virulence (43).

For this purpose, we picked over the 27-amino acid peptide VTV TPL LLG YTF QDS QHN NGG KDG NLT" located at 24-50 position of OmpA at N-terminus region for immunization of mice models. Because there may be limitations to the use of a simple peptide in the immunogenicity that may result in low immune stimulation, the selected peptide was attached to the high molecular weight carrier protein-KLH and admixed with the Freund's adjuvant. In line with the present study, Wang-Lin et al produced anti-OmpA mAbs by immunizing mice with recombinant OmpA and Freund's adjuvant to enhance the immune response and stated that due to the diversity of clinical strains of $A$. baumannii and their resistance to antibiotics, discovering the therapeutic potentials of passive immunization is an essential matter (44).

In the present study, the 3F10-C9 mAb showed positive reactions with OmpA of several antibioticresistant $A$. baumannii pulsotypes in the Western blot and IFA tests. Opsonophagocytosis assays showed in vitro that $\mathrm{mAb}$ had highly efficient bactericidal activities on clinical $A$. baumannii pulsotypes which was associated with a complement-dependent effect. Consistent with the results of this study, T. W. Loehfelm et al. showed that $6 \mathrm{E} 3 \mathrm{mAb}$ against biofilm-associated protein (Bap) detected its epitope in whole-cell lysate of $A$. baumannii 307-0294 in Western blot assay and noted that the Bap antigen is an accessible surface antigen and contains surface-exposed epitopes (45). Weiwei Huang et al. developed passive immunizations against an outer membrane protein with molecular weight of about $22 \mathrm{kDa}$ (Omp22) which had the potentials to be a candidate target for opsonophagocytic killing assay and said that the effects of in-vitro opsonophagocytosis by their antiserum were partly complement-dependent (29). Baig et al. in their study in Canada, produced two mouse mAbs, F241G3sc2 and F241G6sc2, against $A$. baumannii ATCC 19606, but the specific target of the antibodies or the exact epitope of developed mAbs on tested bacterium was almost unknown (20). Another study in Tokyo, Japan, reported the generation of $\mathrm{mAb}$ against OmpA of $E$. coli, although it was not a peptide-based antibody and there is a possibility of cross-reaction with other Enterobacteriaceae (18). In the study by Luo $\mathrm{G}$ et al. anti-OmpA antibodies 
enhanced opsonophagocytic killing of the $A$. baumannii but did not enhance complement-mediated killing (17). It may be due to the serum resistance of some Acinetobacter isolates by binding of $\mathrm{H}$-factor in serum to outer membrane proteins. T. A. Russo et al. stated that the $\mathrm{K} 1$ capsular polysaccharide from A. baumannii could be as a passive immunization target and mAb 13D6 could enhance the in vitro neutrophil-mediated bactericidal activity; however, only $13 \%$ of the $A$. baumannii strains in that study had the $\mathrm{K} 1$ capsular polysaccharide (46). Given that, it appears that polysaccharide capsules are not present in all strains of the $A$. baumannii.

Despite many advances in generation of new antibiotics, we are still witnessing mutations and resistance in microorganisms that threaten human health. Therefore, the design and production of efficient mAbs could be used as an alternative method or in combination with antibiotics to control of drug-resistant infections. There is evidence that immunotherapy by mAbs synergistically improves outcomes in combination with antibiotics. In a recent study, T. B. Nielsen et al. developed a mAb against capsular carbohydrate on the bacterial surface and then assessed the efficacy of administering mAb treatment in combination with colistin; however, the $\mathrm{C} 8 \mathrm{mAb}$, was able to detect only $60 \%$ of $A$. baumannii strains tested (12). In this way, the novel mAb-based therapeutic approaches may be required to achieve sufficient strain coverage ( $90 \%$ coverage) for empirical treatment against MDR, XDR, PDR models of $A$. baumannii infection. Antibodies directed against biomarkers may have the potentials to treat infectious diseases that threaten human health. Moreover, the application of antibodies does not affect the diversity of the host microbiota. In the future, therapeutic antibody preparation and injection into the live model may stimulate macrophages in conjunction with the serum complement system, leading to increased bacterial clearance and prevention of sepsis.

We developed a peptide-based mAb using a simple and reproducible method. The great advantage of this mAb, 3F10-C9, is its binding to OmpA and ability to identify Acinetobacter, as well as opsonization and cooperation in killing bacteria. As limitations of this study, we have not evaluated the usefulness of such monoclonal antibody in an in vivo model nor have we estimated the frequency of resistance to the mAb. However, specific antibodies that target only one biomarker without bactericidal activity are unlikely to develop the bacterial resistance.

Our 3F10-C9 mAb demonstrated the in vitro practical applications including ELISA, Western blot, IFA, and opsonophagocytosis assays which may be appropriate to development of immunological tools required for $A$. baumannii research.

\section{Conclusion}

Antibiotic-resistant $A$. baumannii has emerged as a major cause of healthcare-associated infections worldwide. As good companions of the antimicrobials or novel antibacterial compounds, validated antibodies could confer sufficient protection against $A$. baumannii infections and prevent the development of new drug resistance. 
Our results highlighted the potentials of using OmpA as a conserved antigen among different Acinetobacterisolates. Future characterization of the conserved epitopes in order to further investigate the protective immunity against $A$. baumannii infection is highly desirable.

The produced 3F10-C9 mAb showed a good efficiency in detection, monitoring, and in the opsonization process which offers future applications and perspective on design and production of humanized antibodies for complementary protection. Further studies and more detailed evaluations are needed to perform more accurate and safer in-vivo experiments.

\section{Declarations}

Ethical approval: This study was approved by the Administration Committee of Islamic Azad university, science and research branch (Approval ID: IR.IAU.SRB. REC. 1398. 064).

Consent for publication: all authors understand that the text and any pictures or videos published in the article will be freely available on the internet and may be seen by the general public. The pictures, videos and text may also appear on other websites or in print, may be translated into other languages or used for commercial purposes.

Availability: All supporting data is available through the corresponding author and first author.

Competing interests: The authors declare there are no conflicts of interest.

Funding: No financial benefits have been received or will be received from any party related directly or indirectly to the subject of this article.

Authors' contributions: Omid Yeganeh and Mahdi Shabani developed the original idea and the protocols, abstracted and prepared the manuscript. Mahdi Shabani and Parviz Pakzad participated in the study design, analyzed the data and revised the manuscript. Nariman Mosaffa and Ali Hashemi contributed to study design and data gathering and made useful suggestions. All authors read and approved the final manuscript.

\section{Acknowledgements:}

Special thanks and appreciation to Dr. Makan Sadr (Virology Research Center, National Research Institute of Tuberculosis and Lung diseases (NRITLD), Shahid Beheshti University of Medical Sciences, Tehran, Iran) for their kind help in this research.

\section{First Author information}

Omid Yeganeh : Department of Microbiology, North Tehran Branch, Islamic Azad University, Tehran, Iran. E-mail: yeganeh.omid@yahoo.com, ORCID No: 0000000305127193 


\section{References}

1. Dettori M, Piana A, Deriu MG, Curto PL, Cossu A, Musumeci R, et al. Outbreak of multidrug-resistant Acinetobacter baumannii in an intensive care unit. New Microbiol. 2014 Apr;37(2):185-91. Epub 2014 Apr 1. PMID: 24858645.

2. Harding CM, Hennon SW, Feldman MF. Uncovering the mechanisms of Acinetobacter baumannii virulence. Nature Reviews Microbiology. 2018;16(2):91.

3. Moghadam MT, Mirzaei M, Moghaddam MFT, Babakhani S, Yeganeh O, Asgharzadeh S, et al. The Challenge of Global Emergence of Novel Colistin-Resistant Escherichia coli ST131. Microbial drug resistance. 2021 Apr 28. doi: 10.1089/mdr.2020.0505. Epub ahead of print. PMID: 33913748.

4. Čiginskienė A, Dambrauskienè A, Rello J, Adukauskienè D. Ventilator-associated pneumonia due to drug-resistant Acinetobacter baumannii: risk factors and mortality relation with resistance profiles, and independent predictors of in-hospital mortality. Medicina (Kaunas). 2019 Feb 13;55(2):49. doi: 10.3390/medicina55020049. PMID: 30781896; PMCID: PMC6410055.

5. Breslow JM, Meissler JJ, Hartzell RR, Spence PB, Truant A, Gaughan J, et al. Innate immune responses to systemic Acinetobacter baumannii infection in mice: neutrophils, but not interleukin-17, mediate host resistance. Infection and immunity. 2011;79(8):3317-27.

6. Qiu H, KuoLee R, Harris G, Van Rooijen N, Patel GB, Chen W. Role of macrophages in early host resistance to respiratory Acinetobacter baumannii infection. PloS one. 2012;7(6):e40019.

7. Lei L, Yang F, Zou J, Jing H, Zhang J, Xu W, et al. DNA vaccine encoding OmpA and Pal from Acinetobacter baumannii efficiently protects mice against pulmonary infection. Molecular biology reports. 2019;46(5):5397-408.

8. Dollery SJ, Zurawski DV, Gaidamakova EK, Matrosova VY, Tobin JK, Wiggins TJ, et al. RadiationInactivated Acinetobacter baumannii Vaccine Candidates. Vaccines. 2021;9(2):96.

9. Hübner I, Shapiro JA, Hoßmann Jr, Drechsel J, Hacker SM, Rather PN, et al. Broad Spectrum Antibiotic Xanthocillin X Effectively Kills Acinetobacter baumannii via Dysregulation of Heme Biosynthesis. ACS Central Science. 2021 Mar 24;7(3):488-498. doi: 10.1021/acscentsci.0c01621. Epub 2021 Jan 20. PMID: 33791430; PMCID: PMC8006170.

10. Yeganeh $\mathrm{O}$, Jeddi-Tehrani M, Yaghmaie F, Kamali K, Heidari-Vala H, Zeraati $\mathrm{H}$, et al. A survey on the prevalence of Chlamydia trachomatis and Mycoplasma genitalium infections in symptomatic and asymptomatic men referring to urology clinic of Labbafinejad hospital, Tehran, Iran. Iranian Red Crescent Medical Journal. 2013;15(4):340.

11. Ahmad TA, Tawfik DM, Sheweita SA, Haroun M, El-Sayed LH. Development of immunization trials against Acinetobacter baumannii. Trials in Vaccinology. 2016;5:53-60.

12. Nielsen TB, Pantapalangkoor P, Luna BM, Bruhn KW, Yan J, Dekitani K, et al. Monoclonal antibody protects against Acinetobacter baumannii infection by enhancing bacterial clearance and evading sepsis. The Journal of infectious diseases. 2017;216(4):489-501. 
13. Zurawski DV, McLendon MK. Monoclonal antibodies as an antibacterial approach against bacterial pathogens. Antibiotics. 2020;9(4):155.

14. Choi CH, Hyun SH, Lee JY, Lee JS, Lee YS, Kim SA, et al. Acinetobacter baumannii outer membrane protein A targets the nucleus and induces cytotoxicity. Cellular microbiology. 2008;10(2):309-19.

15. Confer AW, Ayalew S. The OmpA family of proteins: roles in bacterial pathogenesis and immunity. Veterinary microbiology. 2013;163(3-4):207-22.

16. Jahangiri A, Rasooli I, Owlia P, Fooladi AAI, Salimian J. In silico design of an immunogen against Acinetobacter baumannii based on a novel model for native structure of outer membrane protein $A$. Microbial pathogenesis. 2017;105:201-10.

17. Luo G, Lin L, Ibrahim AS, Baquir B, Pantapalangkoor P, Bonomo RA, et al. Active and passive immunization protects against lethal, extreme drug resistant-Acinetobacter baumannii infection. PloS one. 2012;7(1):e29446.

18. Abe Y, Haruta I, Yanagisawa N, Yagi J. Mouse monoclonal antibody specific for outer membrane protein A of Escherichia coli. Monoclonal antibodies in immunodiagnosis and immunotherapy. 2013;32(1):32-5.

19. Nie D, Hu Y, Chen Z, Li M, Hou Z, Luo X, et al. Outer membrane protein A (OmpA) as a potential therapeutic target for Acinetobacter baumannii infection. Journal of biomedical science. 2020;27(1):1-8.

20. Baig A, Cabral TM, Corbett CR. Development and characterization of monoclonal antibodies for rapid detection of Acinetobacter baumannii. Monoclonal antibodies in immunodiagnosis and immunotherapy. 2014;33(4):291-8.

21. Mehdinejadiani K, Bandehpour M, Hashemi A, Ranjbar MM, Taheri S, Jalali SA, et al. In Silico Design and Evaluation of Acinetobacter baumannii Outer Membrane Protein A (OmpA) Antigenic Peptides As Vaccine Candidate in Immunized Mice. Iranian Journal of Allergy, Asthma and Immunology. 2019:655-63.

22. Ghods R, Ghahremani MH, Darzi M, Mahmoudi AR, Yeganeh O, Bayat AA, et al. Immunohistochemical characterization of novel murine monoclonal antibodies against human placenta-specific 1 . Biotechnology and applied biochemistry. 2014;61(3):363-9.

23. Bayat AA, Yeganeh O, Ghods R, Zarnani AH, Ardekani RB, Mahmoudi AR, et al. Production and characterization of a murine monoclonal antibody against human ferritin. Avicenna Journal of Medical Biotechnology. 2013;5(4):212.

24. Bayat AA, Ghods R, Shabani M, Mahmoudi AR, Yeganeh O, Hassannia H, et al. Production and characterization of monoclonal antibodies against human prostate specific antigen. Avicenna journal of medical biotechnology. 2015;7(1):2.

25. Vojgani Y, Shirazi A, Zarei S, Yeganeh O, Jeddi-Tehrani M. Comparison of efficacies of fetal bovine sera from different suppliers in cell culture experiments. Comparative Clinical Pathology. 2018;27(2):519-27. https://doi.org/10.1007/s00580-017-2622-0 . 
26. Beatty JD, Beatty BG, Vlahos WG. Measurement of monoclonal antibody affinity by non-competitive enzyme immunoassay. Journal of immunological methods. 1987;100(1-2):173-9.

27. Salehi B, Ghalavand Z, Mohammadzadeh M, Maleki DT, Kodori M, Kadkhoda H. Clonal relatedness and resistance characteristics of OXA-24 and-58 producing carbapenem-resistant Acinetobacter baumannii isolates in Tehran, Iran. Journal of applied microbiology. 2019;127(5):1421-9.

28. Sugawara E, Nikaido H. OmpA is the principal nonspecific slow porin of Acinetobacter baumannii. Journal of bacteriology. 2012;194(15):4089-96.

29. Huang W, Yao Y, Wang S, Xia Y, Yang X, Long Q, et al. Immunization with a 22-kDa outer membrane protein elicits protective immunity to multidrug-resistant Acinetobacter baumannii. Scientific reports. 2016;6(1):1-12.

30. McConnell MJ, Domínguez-Herrera J, Smani Y, López-Rojas R, Docobo-Pérez F, Pachón J. Vaccination with outer membrane complexes elicits rapid protective immunity to multidrug-resistant Acinetobacter baumannii. Infection and immunity. 2011;79(1):518-26.

31. Huang W, Zhang Q, Li W, Chen Y, Shu C, Li Q, et al. Anti-outer membrane vesicle antibodies increase antibiotic sensitivity of pan-drug-resistant Acinetobacter baumannii. Frontiers in microbiology. 2019;10:1379.

32. Chen W. Current advances and challenges in the development of Acinetobacter vaccines. Human vaccines \& immunotherapeutics. 2015;11(10):2495-500.

33. Alzubaidi ANA, Alkozai ZMF. Immunogenic properties of outer membrane protein of Acinetobacter baumannii that loaded on chitosan nanoparticles. American Journal of BioMedicine. 2017;5(1):1631.

34. Bazmara H, Rasooli I, Jahangiri A, Sefid F, Astaneh SDA, Payandeh Z. Antigenic properties of iron regulated proteins in Acinetobacter baumannii: an in silico approach. International Journal of Peptide Research and Therapeutics. 2019;25(1):205-13.

35. Goel VK, Kapil A. Monoclonal antibodies against the iron regulated outer membrane proteins of Acinetobacter baumannii are bactericidal. BMC microbiology. 2001;1(1):1-8.

36. Gaddy JA, Tomaras AP, Actis LA. The Acinetobacter baumannii 19606 OmpA protein plays a role in biofilm formation on abiotic surfaces and in the interaction of this pathogen with eukaryotic cells. Infection and immunity. 2009;77(8):3150-60.

37. Choi CH, Lee EY, Lee YC, Park TI, Kim HJ, Hyun SH, et al. Outer membrane protein 38 of Acinetobacter baumannii localizes to the mitochondria and induces apoptosis of epithelial cells. Cellular microbiology. 2005;7(8):1127-38.

38. McConnell MJ, Pachón J. Expression, purification, and refolding of biologically active Acinetobacter baumannii OmpA from Escherichia coli inclusion bodies. Protein expression and purification. 2011;77(1):98-103.

39. Viale AM, Evans BA. Microevolution in the major outer membrane protein OmpA of Acinetobacter baumannii. Microbial genomics. 2020;6(6). 
40. Uppalapati SR, Sett A, Pathania R. The outer membrane proteins OmpA, CarO, and OprD of Acinetobacter baumannii confer a two-pronged defense in facilitating its success as a potent human pathogen. Frontiers in microbiology. 2020;11.

41. Darbandian P, Sefid F. Evaluation of OMP A (Outer Membrane Protein A) linear and conformational epitopes in Acinetobacter baumannii. Int J Adv Biotechnol Res. 2016;7(3).

42. Trier N, Hansen P, Houen G. Peptides, antibodies, peptide antibodies and more. International journal of molecular sciences. 2019;20(24):6289.

43. Oskuei RH, Astaneh SDA, Rasooli I. A conserved region of Acinetobacter trimeric autotransporter adhesion, Ata, provokes suppression of Acinetobacter baumannii virulence. Archives of Microbiology. 2021 Aug;203(6):3483-3493. doi: 10.1007/s00203-021-02343-1. Epub 2021 Apr 27. PMID: 33907866.

44. Wang-Lin SX, Olson R, Beanan JM, MacDonald U, Balthasar JP, Russo TA. The capsular polysaccharide of Acinetobacter baumannii is an obstacle for therapeutic passive immunization strategies. Infection and immunity. 2017;85(12).

45. Loehfelm TW, Luke NR, Campagnari AA. Identification and characterization of an Acinetobacter baumannii biofilm-associated protein. Journal of bacteriology. 2008;190(3):1036-44.

46. Russo TA, Beanan JM, Olson R, MacDonald U, Cox AD, Michael FS, et al. The K1 capsular polysaccharide from Acinetobacter baumannii is a potential therapeutic target via passive immunization. Infection and immunity. 2013;81(3):915-22.

\section{Figures}




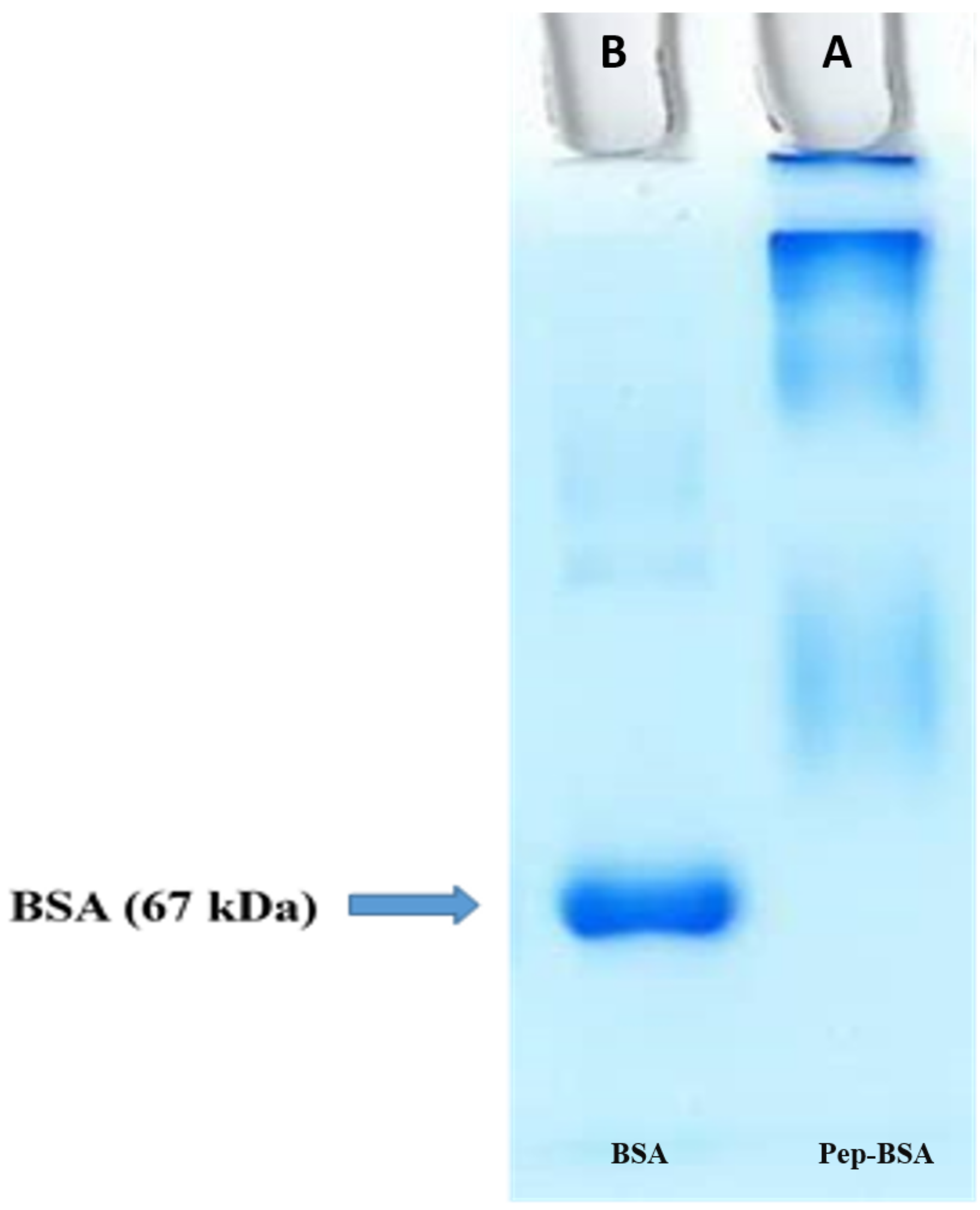

\section{Figure 1}

Conjugation of OmpA-peptide to BSA carrier protein. Lane A): Uprising mobility of peptide-BSA revealed that total immunizing peptide were conjugated to BSA molecules. Lane B): Pure BSA, which appears as a single band in the range of $67 \mathrm{kDa}$ of SDS-PAGE gel. 


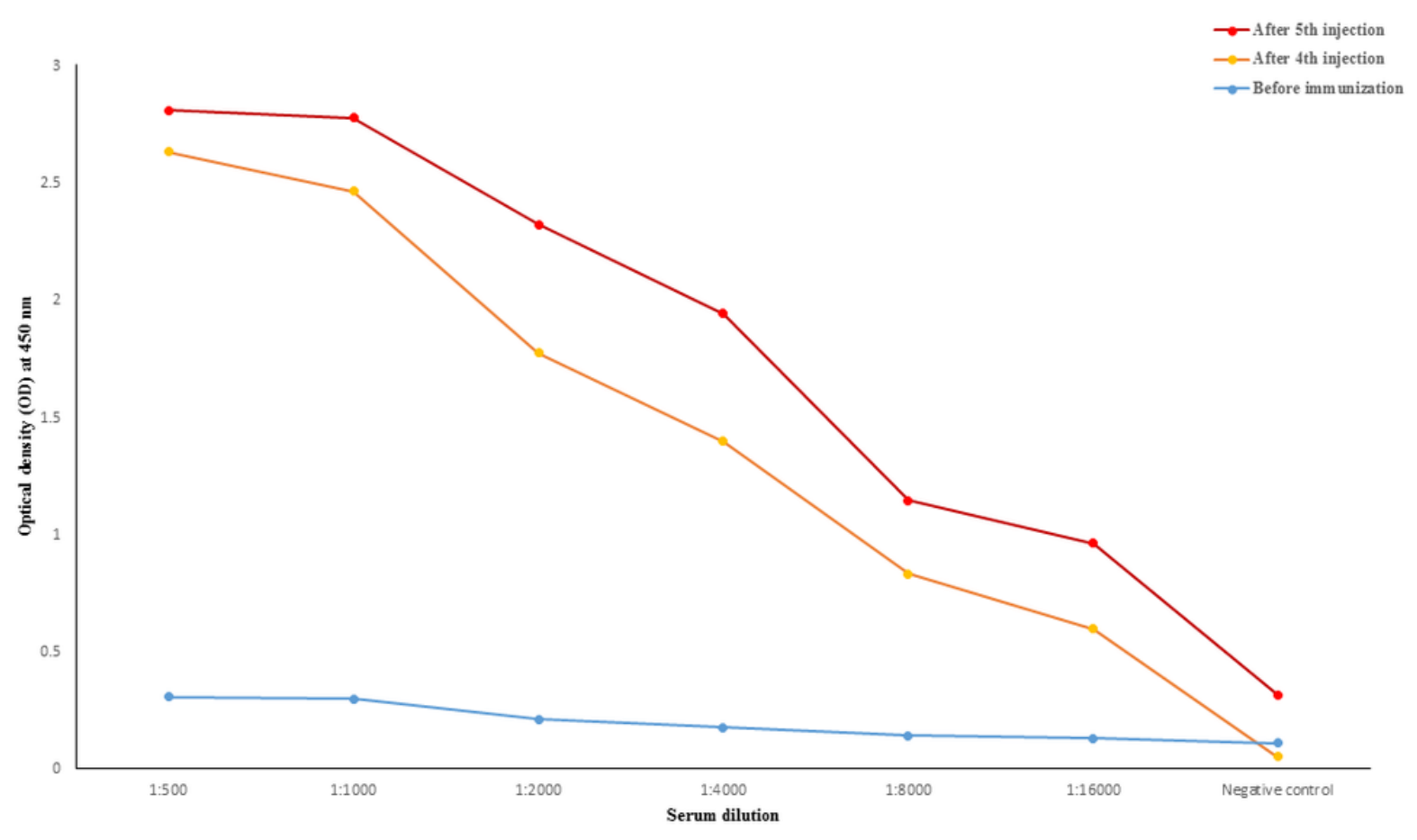

Figure 2

Titration of serum antibody of one of the well-immunized mice with the peptide in separated periods. Prior to immunization, the mice sera were depleted of any desired antibody. The titration was performed from dilution of 1:500 to 1:16000. Phosphate buffer was added instead of the sample to 1-2 wells of each titration column to serve as negative control. The results of serum titration by ELISA showed that one of the treated mice was well immunized after the fifth injection. 


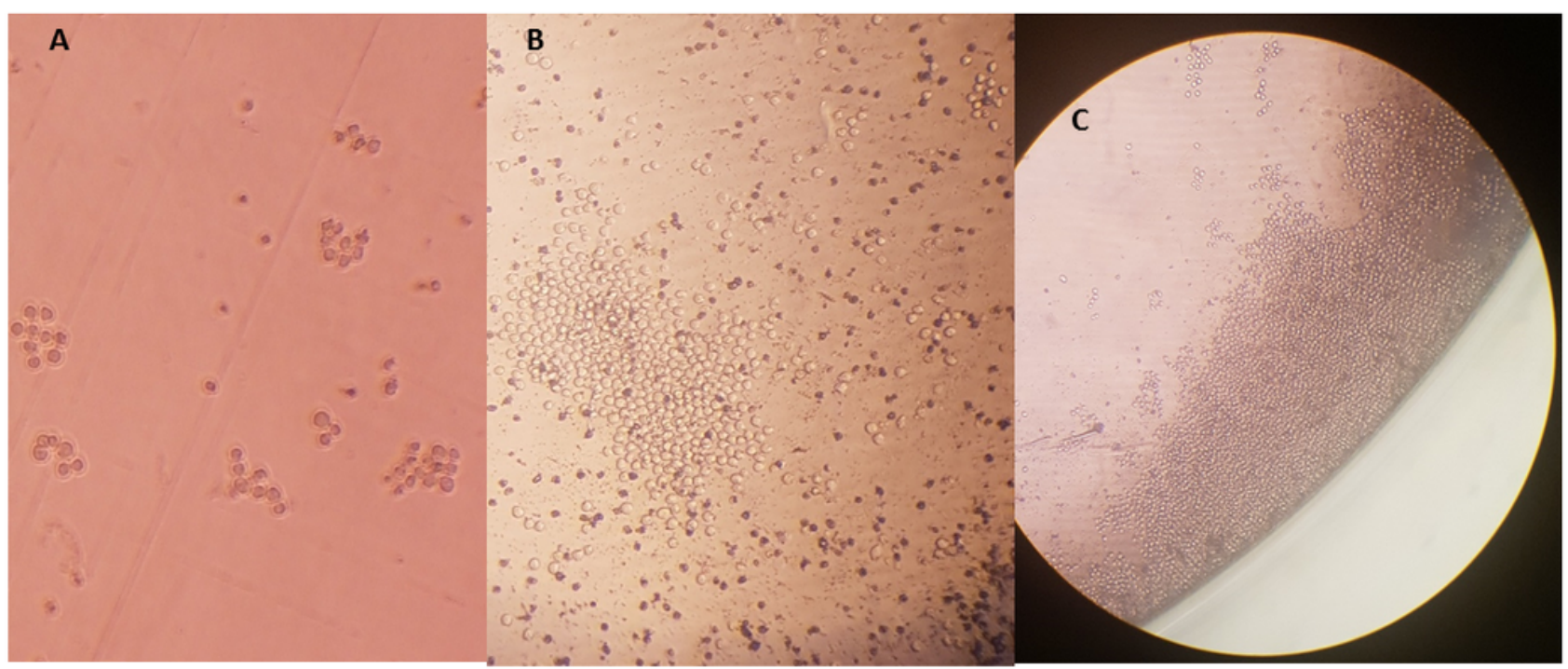

\section{Figure 3}

Stages of hybridoma cell growth. MAbs can be renewably generated once a single clone of hybridoma is developed and the produced mAbs are homogenous and consistent. (A), Initial growth of hybridoma cells after survival in the HAT selected medium. (B), 3F10-C9 monoclone in a growing form. (C), The monoclone in the highly proliferated form. 


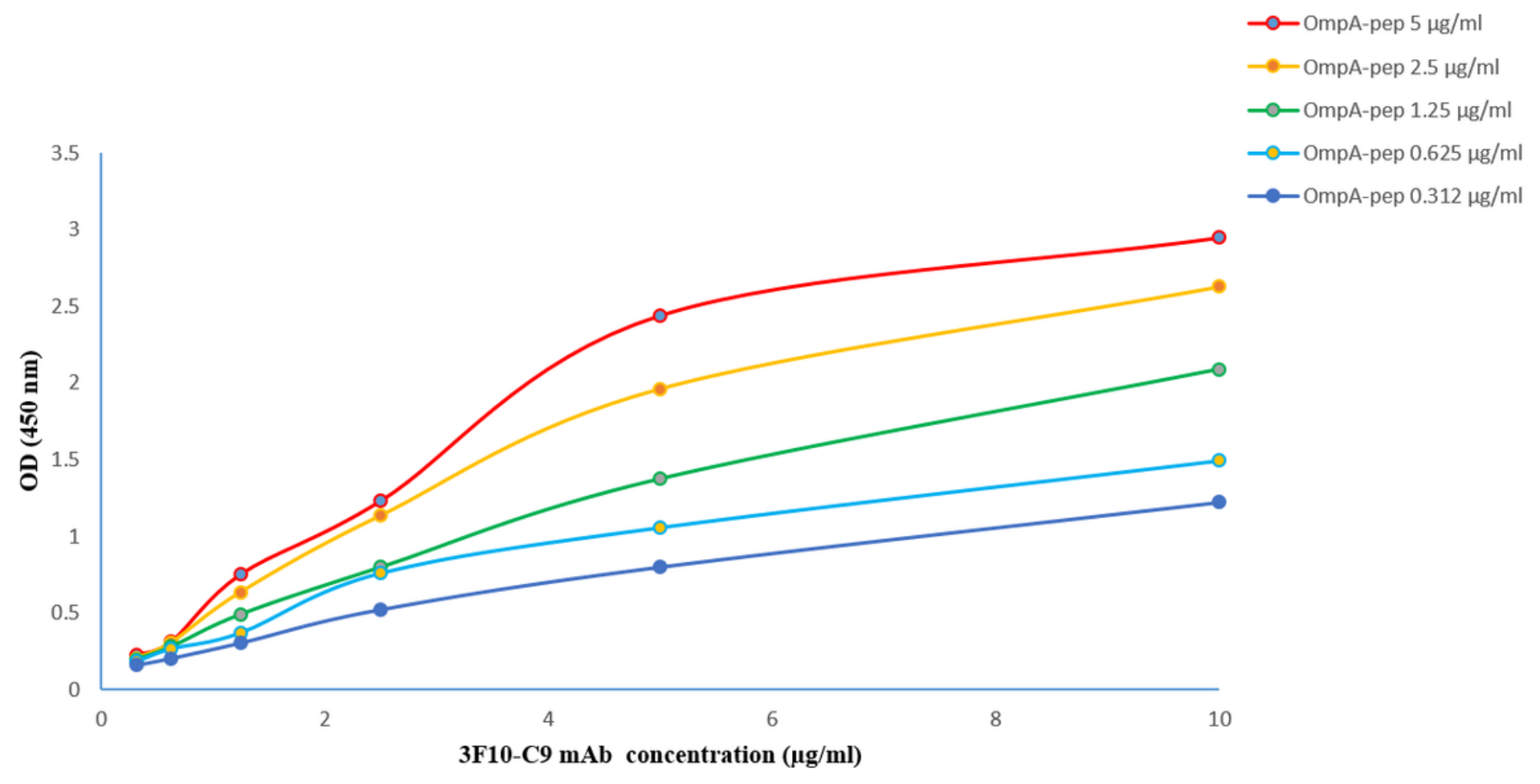

Figure 4

Determination of affinity constant (Kaff) of 3F10-C9 mAb. Serial dilutions of the mAb were titrated on several concentrations of antigen. Five sigmoid curves were plotted according to antigen and antibody concentrations. Then, OD-50 was assigned on each curve as well as the mAb concentration on the X-axis. Kaff of the mAb was obtained based on the entry of antibody concentrations related to OD-50 ([Ab], and $\left[A b^{\prime}\right]$ ) in the corresponding equation. The affinity constant (Kaff) of the 3F10-C9 mAb was calculated to be $1.94 \times 10-9 \mathrm{Mol}$. 

9
$8 \quad 7$
6
54
32
1

$65 \mathrm{kDa}$

$28 \mathrm{kDa}$

\section{Figure 5}

Western blot analysis of the mAb reactivity. OmpA protein is considered as the main nonspecific slow porin of A. baumannii. Since OmpA is a close homolog of E. coli OmpA and P. aeruginosa OprF, the bacterial lysates containing OmpA or similar were resolved in the $10 \%$ acrylamide gel and then exposed to the 3F10-C9 mAb to evaluate the antibody reactivity. Lanes 1-5): Lysates from pulsotypes $A$ to $E$ of $A$. baumannii, Lane 6): BSA-conjugated peptide, Lane 7): E. coli lysate, Lane 8): P. aeruginosa lysate, Lane 9): SeeBlue pre-stained protein standard Marker. The 3F10-C9 mAb reacted with OmpA molecules from Acinetobacter lysates in the range of $28 \mathrm{KDa}$ and reacted with the OmpA-peptide conjugated to the carrier $\mathrm{BSA}$ around $65 \mathrm{KDa}$. No reaction between specific mAb and OmpA homologous proteins was observed in columns 7 and 8 of E. coli and P. aeruginosa. This experiment may be useful in evaluating antibodies for their diagnostic potential. 

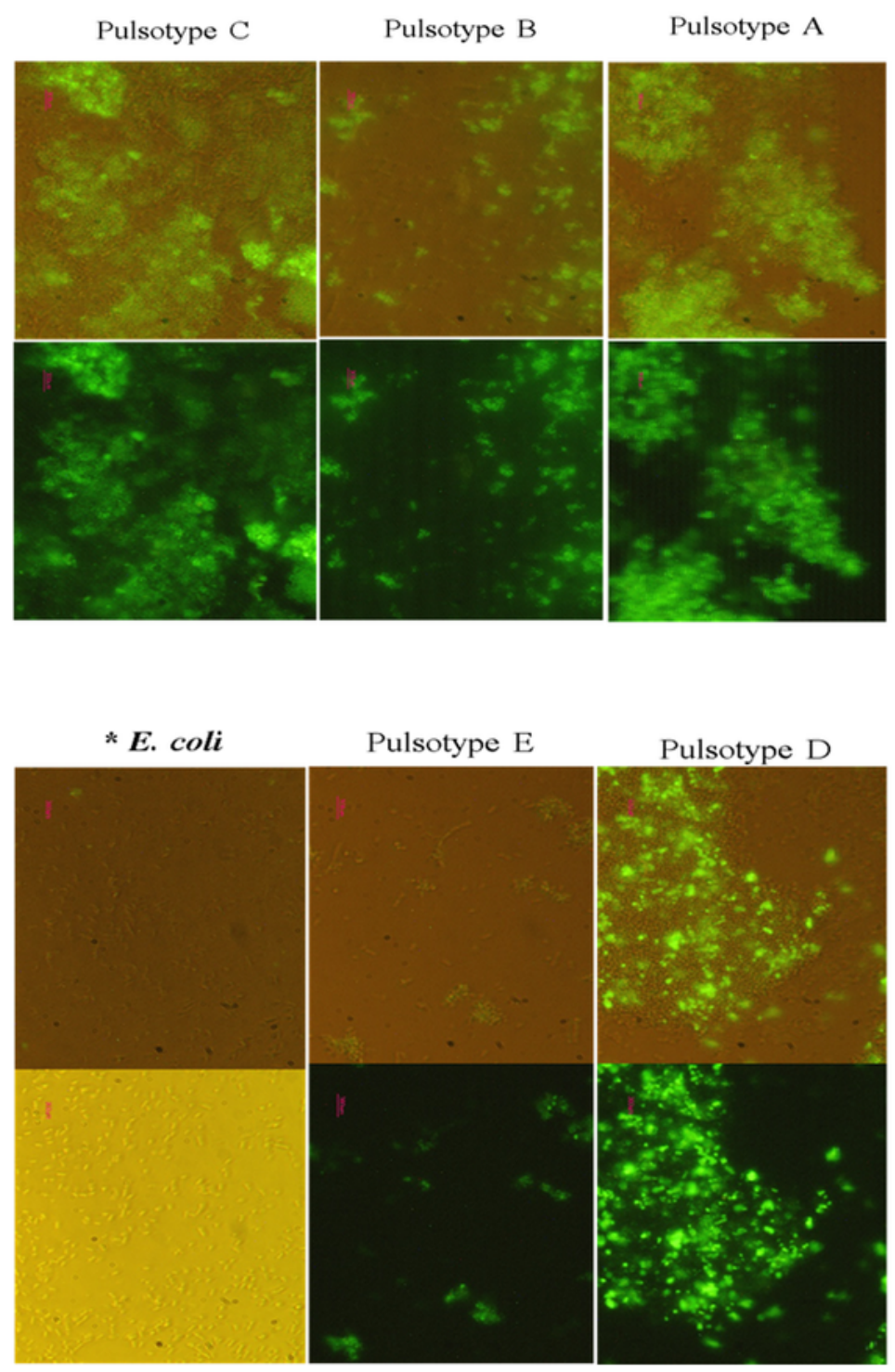

\section{Figure 6}

Detection of Acinetobacter with peptide-based mAb by IFA immunostaining. IFA can potentially be used to evaluate the binding efficacy and specificity of mAbs against specific target such as OmpA of A. baumannii. The 3F10-C9 mAb recognized OmpA antigen on five varied pulsotypes of A. baumannii. In each row, the bacteria are exposed in both normal and UV light modes in one shot of a microscopic image. (Magnification. 40X). The point areas with fluorescent light in each part of the figure represent 
A

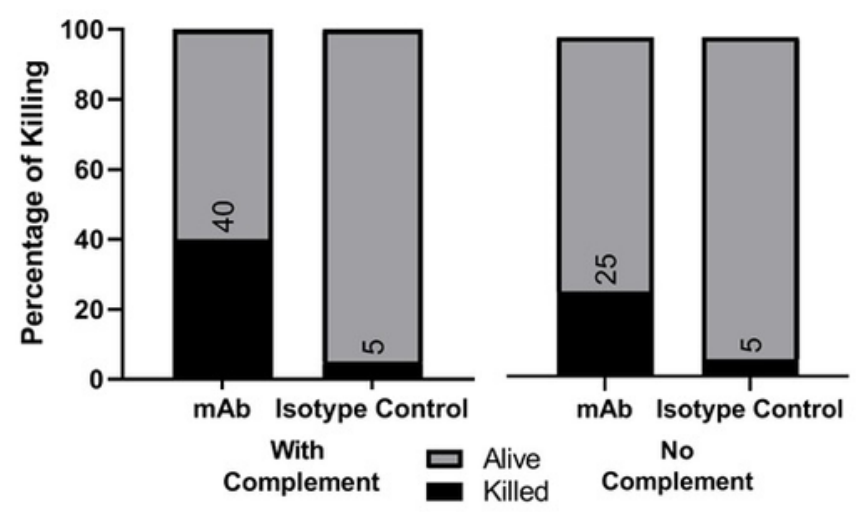

C

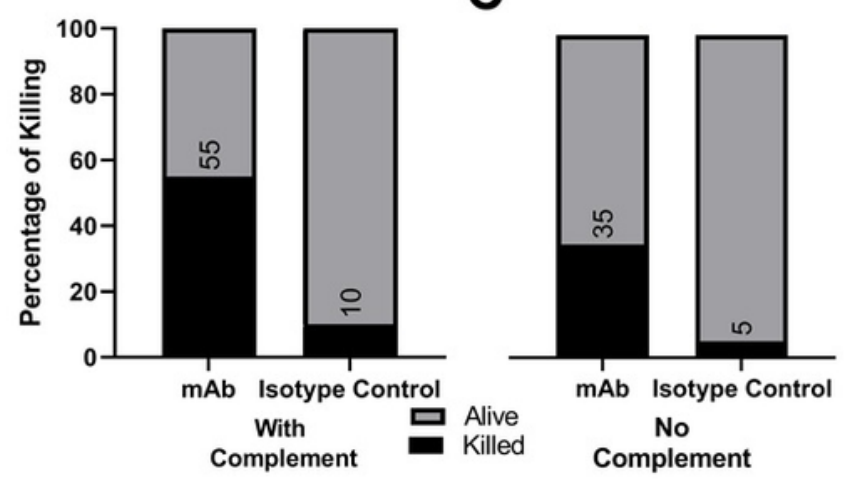

E

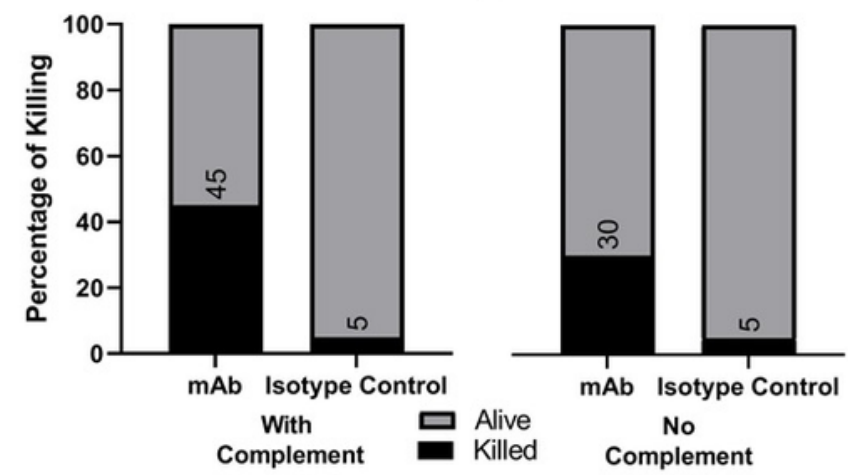

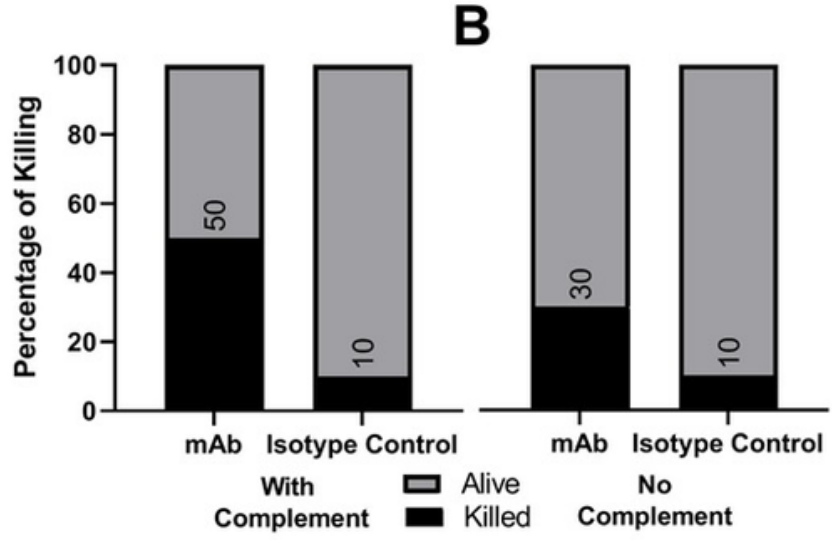

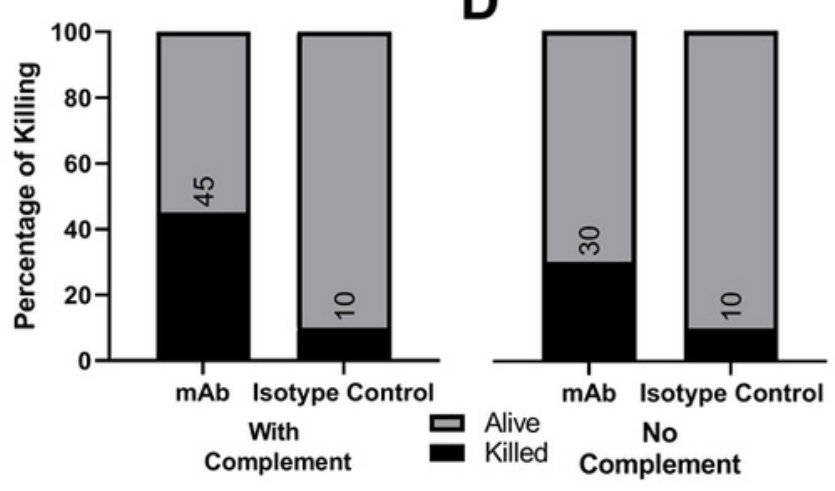

E.coli

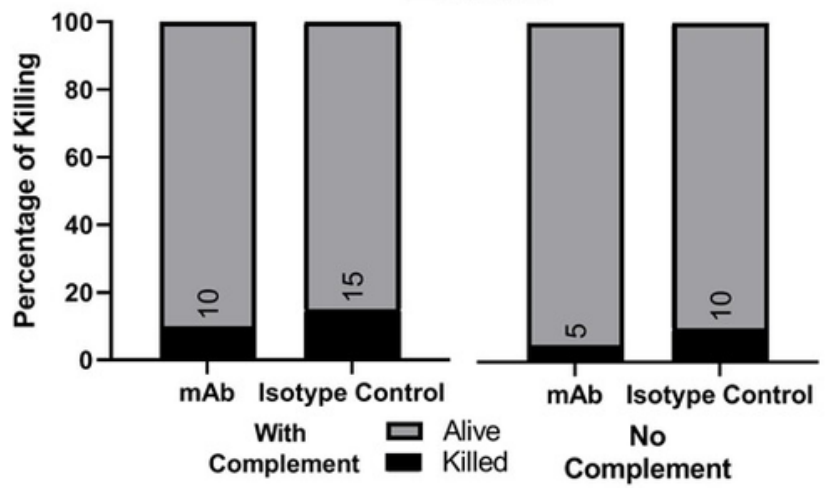

Figure 7 
Evaluation of opsonophagocytic effects of the 3F10-C9 mAb. Antibodies that specifically target a biomarker such as OmpA or others, without bactericidal activity, may desist from triggering bacterial evolution pressure and could be used alone or combined with other antibacterial compounds to apply synergistic effects. In-vitro Opsonization assay with 3F10-C9 mAb showed increasing bactericidal activity of macrophage cells against the various Acinetobacter pulsotypes $(p<0.001)$, and the mAb opsonization in the presence of serum complement showed a greater bactericidal activity. Further, the in vitro opsonophagocytosis with the non-specific antibody (IgG isotype control mAb), did not significantly increase the bactericidal activity against any of the pulsotypes. The opsonization of E. coli with the 3F10$\mathrm{C} 9 \mathrm{mAb}$ and isotype control under different conditions (with and without complement) was not significant. Therefore, the antibody and type of a candidate target could be effective on the opsonization process. ${ }^{*}(A, B, C, D, E)$, represent pulsotypes $A-E$ of $A$. baumannii. 